\title{
A UNIVERSIDADE E A FORMAÇÃO DO ARTISTA-DOCENTE DA(NA) DANÇA
}

Prof $^{\mathrm{a}} \operatorname{Dr}^{\mathrm{a}}$ Cristiane Wosniak ${ }^{1}$

cristianewosniak@yahoo.com.br

\section{INTRODUÇÃO}

A implantação de graduações em Dança no Brasil encontra-se em regime de expansão nos últimos dez anos. Neste panorama, a opção pelas Licenciaturas em Dança constitui-se na tônica predominante, seja no âmbito das instituições públicas ou privadas.

A história dos cursos superiores em Dança no país tem início em 1956 e, segundo Eliana Rodrigues Silva (2016), este pioneiro curso - Escola de Dança da Universidade Federal da Bahia - foi, durante vinte e nove anos, a única possibilidade de formação em dança no nível superior. Para Silva, a Escola de Dança da UFBA, desde sua origem "se consolidou como centro difusor da criação artística e do pensamento teórico em dança contemporânea" (SILVA, 2016, p. 31).

Somente na década de oitenta, outros três cursos superiores de dança foram implantados no país. Em Curitiba, a Pontifícia Universidade Católica do Paraná, em convênio com a Fundação Teatro Guaíra (1984), criava o curso de Bacharelado e Licenciatura em Dança ${ }^{2}$ com dupla habilitação. No Rio de Janeiro, no mesmo ano, a UniverCidade (1984) criava a Licenciatura em Dança e em Campinas, na Unicamp (1986) a dupla habilitação também era a opção da graduação.

\footnotetext{
1 Doutora em Comunicação e Linguagens pela UTP-PR (linha de pesquisa: Estudos de Cinema e Audiovisual). Mestra pelo mesmo programa. Professora Adjunta da UNESPAR - campus de Curitiba II/Faculdade de Artes do Paraná (cursos de Bacharelado em Cinema e Audiovisual e Bacharelado e Licenciatura em Dança). Email: cristiane_wosniak@yahoo.com.br

2 Em 04/10/1993, foi aprovada a transferência do Curso de Dança - com habilitações em Bacharelado e Licenciatura - da PUCPR para a Faculdade de Artes do Paraná, instituição de Ensino Superior, pública e estatal. Atualmente, desde 25/10/2001, a Faculdade de Artes do Paraná foi integrada à Universidade Estadual do Paraná e tornou-se o campus de Curitiba II da UNESPAR. A UNESPAR é uma instituição de ensino superior pública mantida pelo Governo do Estado do Paraná. Possui campi

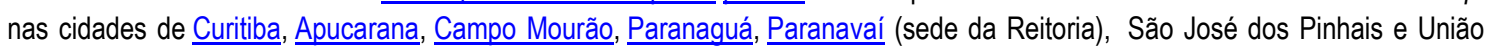
da Vitória.
} 
Devo chamar a atenção para esta dupla habilitação simultânea, ainda em voga em algumas instituições de ensino superior - artista e docente - ou mais precisamente, bacharelado e licenciatura, atuando concomitantemente na formação do que se entende, na contemporaneidade, por artista-docente. Acredito firmemente no fluxo incessante entre as dimensões pedagógicas e artísticas: entre a criação artística, a pesquisa e a prática docente na formação do artista da dança no âmbito do ensino superior.

Observo que estes anseios também fazem parte do raciocínio de Ana Maria Rodriguez Costas em seu artigo 'Para além das normatizações, pulsar saberes' (2016), ao afirmar sua crença em que "a formação do profissional da dança se amplia quando focaliza a dimensão pedagógica" (COSTAS, 2016, p. 130).

Seja a opção por Bacharelado ou Licenciatura, é possível afirmar que nos últimos anos, as instituições de ensino superior no Brasil tornaram-se sensíveis às propostas de criação, implantação e ampliação de ofertas de graduações e pós-graduações em dança no país: em 2002, segundo Márcia Strazzacapa (2006), “existiam 15 cursos de graduação e mais de 30 de pós-graduação - especialização, mestrado e doutorado" (STRAZZACAPA, 2006, p. 12).

Entretanto, ao analisarmos atentamente as estatísticas atuais no site do INEP ${ }^{3}$, por exemplo, e também o que descreve Silva (2016), o crescimento exponencial de cursos de graduação pode ser mapeado da seguinte forma: "16 instituições federais, 5 estaduais e 9 particulares oferecem 27 cursos de licenciatura e 14 de bacharelado, totalizando hoje 41 cursos de graduação em Dança no país" (SILVA, 2016, p. 31).

Levando-se em consideração a estatística anteriormente descrita, percebe-se que o mapeamento foi realizado em 2016 e o curso de Licenciatura em Dança da FURB ainda não havia sido registrado. Somam-se, em 2017, portanto, 42 cursos ativos de graduação em Dança, distribuídos por vários estados e regiões do país.

Atuando como docente no ensino superior há dezenove anos, acredito que o número de cursos em funcionamento contínuo no país ainda é insuficiente, se comparado à oferta de cursos de graduação na área de Artes Visuais ou Educação Física, por exemplo, mas também considero um avanço numérico significativo,

\footnotetext{
3 Para maiores informações sobre instituições de ensino superior, cursos de graduação, avaliações do MEC, consultar o site: $<w w w . e d u c a c a o s u p e r i o r . i n e p . c o m . b r / f u n c i o n a l / l i s t a \_c u r s o s . a s p>$. Acesso em 12 set 2017. 
principalmente ao verificar a porcentagem de profissionais titulados e o visível aumento de publicações na área específica da Dança nos últimos anos.

\section{AS TRANSVERSALIDADES DA(NA) FORMAÇÃO DOS ARTISTAS DA DANÇA}

O que constitui a formação do artista da dança no Brasil? Como se pronuncia a Classificação Brasileira de Ocupações (CBO) na qualificação dos profissionais atuantes na dança? Por que os artistas da dança procuram um curso superior? Bacharelado ou Licenciatura: quais são as especificidades de cada habilitação? O que dizem as Diretrizes Curriculares Nacionais sobre os curso de graduação em Dança? Ser artista ou professor de dança?

Artista e professor não são profissões antagônicas, mas também não são sinônimas, embora, uma não negue a outra. Os cursos de graduação em dança no país têm adotado a perspectiva da complementaridade, ou seja, uma habilitação complementa a outra. Entretanto, estas duas modalidades nem sempre pertenceram à mesma 'família'.

Segundo a Lei no 6.533, e o Decreto no 82.385 de 05 de Outubro de 1978, a regulamentação do Artista e Técnico em Espetáculos de Diversões definia quem era o artista - bailarino(a) ou dançarino(a) - em território nacional:

\footnotetext{
O bailarino ou dançarino é aquele que executa danças através de movimentos coreográficos, pré-estabelecidos ou não; ensaia seguindo a orientação do coreógrafo, atuando individualmente ou em conjunto, interpretando papeis principais ou secundários; pode optar pela dança clássica, moderna, contemporânea, folclórica, popular ou shows; pode ministrar aulas de dança em academias ou escolas de dança, reconhecidas pelo Conselho Federal de Educação, obedecidas as condições para registro como professor.
}

Hoje, segundo a Classificação Brasileira de Ocupações $(C B O)^{4}$ atualizada em 2002, que define em cada área o quadro das ocupações inseridas em seu contexto, na família 'artistas da dança' estão presentes as seguintes categorias: 1) assistente de coreografia; 2) bailarino (bailarino criador, bailarino intérprete, dançarino); 3)

\footnotetext{
${ }^{4}$ A CBO é um documento normalizador do reconhecimento da nomeação e da codificação dos títulos e conteúdos das ocupações do mercado de trabalho brasileiro, atualizado em 2002, após 20 anos. Para maiores informações, consultar o site: $<$ www.mtecbo.gov.br>. Acesso: 11 set. 2017. 
coreógrafo (bailarino coreógrafo, coreógrafo bailarino); 4) dramaturgo de dança; 5) ensaiador de dança; 6) professor de dança (maître de ballet).

Este reconhecimento implícito no quadro da CBO, admite que a formação do professor de dança possa/deva ser contaminado e permeado pela prática artística.

De acordo com Carla Morandi (2006), "a atuação do professor de dança passa pela aprendizagem do ofício e só pode ser feita por um artista. Não está na categoria de professor, mas de artista da dança" (MORANDI, 2006a, p 107).

Atento para o fato da ampliação do campo de atuação do artista da dança que, atualmente, escoa para além das possibilidades conjugadas na CBO. As funções a serem desempenhadas no campo das artes híbridas como a pesquisa/criação de videodanças, filmes de dança, documentários, a ocupação de um espaço gerado pela necessidade de promover políticas públicas e configurações de editais de fomento e incentivo à prática e pesquisa em dança, a necessidade do desempenho de funções empresariais, diretivas e de curadorias de festivais, mostras e eventos de dança, além de outras possibilidades, são uma realidade a ser incorporada no campo de atuação dos artistas da dança.

Ao acreditar que o professor de dança é, antes de tudo, um artista, o curso de Licenciatura em Dança da FURB já nasce a partir de uma proposta pedagógica atualizada. De acordo com as informações obtidas no site da instituição e que nortearam a palestra por mim proferida na ocasião da aula inaugural,

o curso de licenciatura em Dança da FURB é o primeiro curso de dança do estado de Santa Catarina, e prepara o estudante para exercer a profissão de professor e bailarino [grifo meu] por meio de estudos teóricos e práticos. A formação dança deste curso terá o foco na docência, no pesquisador e no artista, sendo essa constituída em um núcleo: Formação didáticopedagógica, e quatro campos: Disposição Poética; Formação estética/estésica e ética, Formação teórica e Competências Técnicas. Desta forma O Licenciado em Dança da Universidade Regional de Blumenau constitui-se num professor-artista-pesquisador [grifo meu] capaz de assumir a função de agente da transformação sociocultural por meio da Dança, que conhece e domina as técnicas e metodologias da dança e da docência em dança, numa perspectiva crítica diante da realidade artística e educacional com vistas à compreensão, análise e interação das manifestações culturais. É um professor-artista-pesquisador sensível às novas formas de expressão, com base em referenciais históricos, culturais e estéticos que sustentem um olhar e uma prática contemporâneos, com 
espírito de pesquisador e produtor de conhecimentos na dança e na pedagogia em dança para espaços formais e não formais de educação. ${ }^{5}$

Destaco um importante papel das instituições de ensino superior na formação do artista-docente e que tão coerente e assertivamente é destacado na descrição do curso de Licenciatura em Dança da FURB: o incentivo à pesquisa.

Atualmente, existem diversos formatos de incentivo à pesquisa na graduação que vão desde à estruturação dos trabalhos de conclusão de curso (TCC) à participação discente em Programas de Iniciação Científica e Artística com remuneração/bolsa ou de forma voluntária.

Silva (2016) corrobora esta perspectiva ao afirmar que "desde o começo da sua formação é possível familiarizar o aluno com técnicas e instrumentos de pesquisa, que serão úteis ao longo da sua vida profissional, mesmo que não se dedique diretamente ao ensino formal ou acadêmico" (SILVA, 2016, p. 34).

Outro detalhe importante na descrição/definição do curso da FURB é a menção à preocupação da instituição e do próprio curso, com o entorno social, cultural e extensionista: "o vale do Itajaí destaca-se pelos inúmeros grupos de dança independentes e estúdios de dança particulares. Uma graduação em dança na FURB, por estar dentro de uma Universidade, estará fortemente ligada ao ensino, pesquisa, extensão e cultura [grifo meu]." ${ }^{6}$

A maioria dos artistas da dança se forma à margem do contexto acadêmico, em uma transversalidade que é inerente ao campo das artes. É notória a afirmação de que o ambiente universitário não é o único espaço onde se produz os profissionais da dança. Entretanto, a perspectiva da formação do artista-docente-pesquisador, pode e deve, ser um diferencial no momento da opção pela formação no âmbito da universidade.

Dulce Aquino em seu artigo Dança e universidade: desafio à vista (2002), observava que esta procura pela pesquisa, reflexão crítica, criação artística e prática docente, ou seja, esta "perspectiva de atuação em um mercado de trabalho mais

\footnotetext{
${ }^{5}$ A descrição do curso de Licenciatura em Dança da FURB foi retirada do site da instituição e pode ser acessada no endereço: $<$ http://www.furb.br/web/5171/cursos/graduacao/cursos/danca/apresentacao>. Acesso: 04 ago. 2017.
} 
diversificado e exigente tem atraído uma nova geração de artistas para o ambiente universitário" (AQUINO, 2002, p. 40).

Esta diversidade de alunos e alunas que chegam à universidade vem permeada e impregnada da prática de diversos tipos de vivência cultural, artística e diferentes formações em(na) dança. Portanto, é função da universidade e, de seu curso de graduação, dar vazão a estas experiências prévias, incluir estes saberes no processo de ensino-aprendizagem das diferentes modalidades de danças praticadas no âmbito universitário e fazer circular estas informações dentro e fora do espaço acadêmico.

Ana Terra, em seu artigo Onde se produz o artista da dança? (2010, p. 73), corrobora esta assertiva: "à universidade, cabe ainda, a articulação do ensino, a produção da pesquisa e a extensão a qual implica em estabelecer um diálogo com a sociedade, ou seja, a circulação do conhecimento ali produzido."

Relembro a todos os presentes no auditório da FURB, que é no universo acadêmico que além de dançar, e muito, os alunos e as alunas poderão ampliar seus conhecimentos na área: refletir, questionar, criticar, pesquisar, documentar as possibilidades da dança em seu contexto histórico local, regional, nacional ou internacional, criar, conhecer novas possibilidades de movimento, de diferentes tecnologias aplicadas à dança e às artes, trocar experiências com alunos e alunas de outros cursos ou áreas afins, compreender sua atuação como profissionais - artistas da dança - e cidadãos e cidadãs conscientes na educação e na sociedade. As graduações em dança formam muito mais do que o bailarino ou a bailarina.

Destaco o privilégio dos calouros e calouras do curso de Licenciatura em Dança da FURB que poderão participar de projetos de extensão com comprovada qualidade e que os precedem na instituição: 1) Grupo de Danças Alemãs da FURB; 2) Grupo de Danças Urbanas da FURB; 3) Grupo de Danças de Salão da FURB; 4) Grupo de Dança Contemporânea da FURB e 5) O projeto Arte na escola.

Segundo Márcia Strazzacapa em seu livro Entre a arte e a docência: a formação do artista da dança (2006), os cursos de dança no Brasil, formam: 
Mas para se entrar na universidade, precisa-se já ter estudado e vivenciado a dança, daí o papel fundamental das academias e escolas livres de dança. As faculdades precisam das academias tanto quanto as academias precisam das faculdades de dança. Essa simbiose é mais que salutar, é necessária, é fundamental (STRAZZACAPA, 2006, p. 13).

Assim, a Dança, como área de conhecimento autônoma vem constantemente ampliando seu espaço e conquistando, lentamente, porém, persistentemente, seu reconhecimento e mérito, no ambiente acadêmico, gerando novos cursos de graduação e pós-graduação no país e propiciando, desta maneira, a diversificação do campo de atuação dos artistas da dança.

\section{A LICENCIATURA EM DANÇA DA FURB: INTERLOCUÇÃO COM AS GRADUAÇÕES EM DANÇA NO BRASIL}

Os Cursos Superiores de Dança, no Brasil, encontram-se devidamente regulamentados pelo Conselho Federal de Educação e são aprovados pelo Ministério da Educação e Cultura (MEC) que outorga aos graduados a seguinte diplomação: bacharel em dança (Bacharelado - duração 4 anos), licenciado em dança (Licenciatura Plena - duração 4 anos) ou tecnólogo em dança (Técnico Superior - duração de 3 ou 2 anos).

O curso de Licenciatura Plena dá direito aos graduados, de exercer a profissão de professor no ensino regular - fundamental e médio. As faculdades estatais, ainda têm a fiscalização das Secretarias Estaduais de Educação e seus respectivos Conselhos Estaduais de Educação.

O curso de Licenciatura em Dança da FURB encontra-se inserido na estatística que aponta a crescente oferta de cursos de licenciatura, nos últimos três anos. Este fato, com certeza, reflete o que preconiza a Nova Lei de Diretrizes e Bases da Educação Nacional (LDB) prevendo que o ensino de arte passa a ser obrigatório nas escolas de ensino fundamental, e que a dança deve ser contemplada, ao lado das demais linguagens artísticas, como o teatro, a música e as artes visuais.

A legislação nacional observa que, para atuar na escola regular, o professor deve possuir diploma de licenciatura. Aos poucos, presume-se que, para ensinar a 
linguagem artística da dança na escola, apenas o licenciado em dança estará habilitado.

Os projetos pedagógicos dos cursos de Licenciatura necessitam, desde $2002^{7}$, contemplar 400 horas de práticas de ensino a serem distribuídas ao longo dos 4 anos de duração do curso, incluindo-se nesta prática o Estágio Supervisionado no ambiente escolar.

O amplo mercado de trabalho, aberto aos licenciados em dança a partir da nova LDB, contribuiu para o aumento da implantação de cursos superiores nesta área e viceversa. Mas, ainda é precária a situação de contratação, mediante concurso público, por exemplo, destes profissionais especializados, na área da arte-dança-educação.

Todos os cursos de graduação em Dança no Brasil devem observar as Diretrizes Curriculares Nacionais, atualizadas e aprovadas por meio da Resolução CNE/CES 3/2004, publicada no Diário Oficial da União, Brasília, em 12 de março de 2004, Seção 1, p. 11.

Tais Diretrizes, entretanto, asseguram às instituições de ensino superior, ampla liberdade na composição da carga horária a ser cumprida para a integralização dos currículos, que, longe de serem uniformes, em território nacional, podem ser, desta forma, flexibilizados, de acordo com as realidades educacionais, em sua contextualização, nos diferentes estados brasileiros.

Os primeiros cursos de dança implantados no Brasil passaram pelo crivo do Conselho Federal de Educação, que por meio da Lei de Diretrizes e Bases da Educação Nacional 4.024/61, em seu art. 9o e a Reforma Universitária 5.540/68, no art. 26, estabelecia [obrigatoriamente] a fixação de currículos mínimos para os cursos de graduação, válidos para todo o Brasil, os quais foram concebidos com as seguintes finalidades: 1) facilitar transferências entre instituições, de uma localidade para outra, com integralizações curriculares; 2) fornecer diplomas profissionais assegurando o exercício da profissão; 3) assegurar uma uniformidade 'profissionalizante' mínima, diferenciados apenas em relação às disciplinas optativas e complementares; 4) uniformizar o tempo de integralização do curso (tempo mínimo, médio e máximo); 5)

\footnotetext{
${ }^{7}$ Estas alterações/normatização foram propostas por dois documentos básicos: 1) a Resolução CNE/CP no. 1 - de 18/02/2002 (consultar ref. BRASIL, 2002a); 2) Resolução CNE/CP no. 2 - de 19/02/2002 (consultar ref. BRASIL, 2002b). 
observar normas gerais para o país, onde o estudante tivesse garantia de igualdade de oportunidades em qualquer instituição de ensino superior;

Este modelo vigorou durante muito tempo, no Brasil, e, seguindo esta perspectiva, o primeiro curso superior - Escola de Dança da UFBA - gerou o 'modelo padrão' a ser adotado pelos demais cursos de dança.

Segundo Aquino (2002):

\begin{abstract}
as qualidades do currículo mínimo se refletiam nas concepções das matérias necessárias para a formação do dançarino e do professor de dança. Esse currículo consistia num conjunto de matérias básicas que permitiam um consistente lastro teórico na abordagem da dança como objeto de estudo na área de história e filosofia da arte. O apoio científico para o conhecimento do corpo, através da anatomia, fisiologia e cinesiologia e o estudo de elementos de música, como área de conhecimento imprescindível para o futuro profissional, fazem parte, também, do elenco desse núcleo básico (AQUINO, 2002, p. 44-45).
\end{abstract}

As propostas elaboradas por meio dos 'currículos mínimos', rigidamente concebidos na norma, não permitiam o alcance da qualidade e particularidades almejadas. Ao contrário: inibiam a inovação e o diálogo com a contemporaneidade, impossibilitando, muitas vezes, a formação de um profissional apto para a adaptabilidade e para a diversidade.

Com a publicação da Lei 9.131 , de 24/11/95, o art. 9으, parágrafo 2ํ, alínea 'c', conferiu à Câmara de Educação Superior do Conselho Nacional de Educação, a competência para a elaboração do projeto de Diretrizes Curriculares Nacionais - DCN que orientarão [não obrigarão] os cursos de graduação, a partir de propostas a serem enviadas pela Secretaria de Educação Superior do Ministério da Educação ao CNE, tal como viria a estabelecer o atual inciso VII do art. 9o da nova LDB 9.394/96, de 20/12/96, publicada em 23/12/96.

Posteriormente, em 1997, a CES/CNE, aprovou o Parecer 776/97, no qual estabelece que as Diretrizes Curriculares Nacionais devem: a) se constituir em orientações para elaboração dos currículos; b) ser respeitadas em todas as instituições de ensino superior; c) assegurar a flexibilidade e a qualidade de formação oferecida aos estudantes. 
As atuais Diretrizes Curriculares para os cursos de graduação, servem de referência para as instituições, na organização de seus programas curriculares de formação superior, permitindo flexibilidade e induzindo a criação de diferentes perfis profissionais, garantindo uma maior diversidade de carreiras, o que vai ao encontro da nova $\mathrm{CBO}$, refletindo, desta forma a heterogeneidade das demandas sociais e artísticas emergentes.

Desta forma, foram estabelecidas, a partir das orientações gerais contidas nos Pareceres CES/CNE 776/97 e 583/2001, bem como nos desdobramentos decorrentes do Edital 004/97-SESu/MEC, as Diretrizes Curriculares Nacionais e as Diretrizes Curriculares Gerais dos Cursos de Graduação, observando-se que o art. 3o da Resolução CNE/CES 3/2004, sugere os seguintes parâmetros a serem 'desejados' como perfil de um graduando em Dança:

Capacitação para a apropriação do pensamento reflexivo e da sensibilidade artística, comprometida com a produção coreográfica, com espetáculo da dança, com a reprodução do conhecimento e das habilidades, revelando sensibilidade estética e cinesiologia, inclusive como elemento de valorização humana, da autoestima e da expressão corporal, visando a integrar o indivíduo na sociedade e tornando-o participativos de suas múltiplas manifestações corporais.

A partir de tais recomendações a equipe de docentes da FURB, que formulou o Projeto Pedagógico do curso de Licenciatura em Dança ${ }^{8}$, destaca que:

- Licenciado em Dança da FURB se constituirá num professor-artistapesquisador capaz de assumir a função de agente da transformação sociocultural por meio da Dança, que conhece e domina as técnicas e metodologias da dança e da docência em dança, numa perspectiva crítica diante da realidade artística e educacional com vistas à compreensão, análise e interação das manifestações culturais. 9

\footnotetext{
${ }^{8}$ A comissão de criação do curso de Licenciatura em Dança da FURB foi composta pelos professores da instituição, Carla Carvalho, Karla Lucia Bento, Marco Aurelio da Cruz Souza e Roberto Murphy constituída pela Portaria 00612017, e tiveram apoio incondicional da professora Rita Buzzi Rausch, diretora do Centro de Ciências da Educação, Artes e Letras (CCEAL) e do reitor João Natel.

${ }^{9}$ Esta descrição do perfil do ingressante foi retirada do site da FURB, no campo que descreve o novo curso de graduação, especificamente no endereço: <http://www.furb.br/web/2164/servicos/outros-portais/servidor-furb/apresentacao/noticias/furblanca-primeiro-curso-de-danca-de-santa-catarina/6370>. Acesso: 05 ago. 2017.
} 
É muito importante ressaltar que o perfil identitário do curso da FURB pretende focalizar os diálogos entre as danças populares e contemporâneas, enfatizando o pertencimento social destas danças no espaço acadêmico e vice-versa, podendo, desta forma, encurtar as distâncias territoriais do Estado. No site da instituição, no item que apresenta em linhas gerais os objetivos do curso, percebe-se que o ensejo da formação se dará pelo foco da docência permeada pela prática/reflexão artística e pelo atravessamento da pesquisa em todo o processo formativo. "A formação em dança deste curso terá o foco na docência, no pesquisador e no artista, sendo essa constituída em um núcleo: Formação didáticopedagógica, e quatro campos: Disposição Poética; Formação estética/estésica e ética, Formação teórica e Competências Técnicas" ${ }^{10}$

Para além dos estudos e práticas de(sobre) danças na universidade, saliento a relevância das atividades complementares mantidas nos currículos com a finalidade de chamar a atenção do corpo discente para determinadas atividades independentes, opcionais, de formas e organizações interdisciplinares, sobretudo nas relações com o mundo do trabalho e com as diferentes manifestações e expressões culturais e artísticas, com as inovações tecnológicas, incluindo ações de extensão junto à comunidade, projetos integrados a outros cursos e áreas afins. Tais atividades, normalmente se reportam a um regulamento próprio.

A nova LDB preconiza que o Projeto Pedagógico de um curso de Dança deve possuir uma clara concepção de quais são as particularidades deste curso, abrangendo em seus aspectos estruturais uma clara contextualização em relação às suas inserções institucional, política, geográfica e social.

A FURB demonstra, a meu ver, uma preocupação e interesse legítimo com a demanda cultural de seu entorno social. No site institucional pode-se perceber este interesse ao se destacar que o curso de Licenciatura em Dança pretende preencher a lacuna existente na região do Vale de Itajaí no que se refere à formação docente coerente com as especificidades da atualidade e à pesquisa em arte no que tange a processos metodológicos de ensinoaprendizagem, processos criativos e teoria em dança.

\footnotetext{
10 Para maiores informações, consultar: <http://www.furb.br/web/5171/cursos/graduacao/cursos/danca/apresentacao >. Acesso: 05 ago. 2017.
} 
Em entrevista ${ }^{11}$, o coordenador do curso destaca as evidências da necessidade urgente de abertura de um curso superior de Dança no Estado e exulta com a possibilidade aberta pela FURB para tal empreitada, visto que Santa Catarina possui forte tradição na prática e na promoção de dança: 1) Joinville foi a cidade escolhida para acolher a Escola do Teatro Bolshoi no Brasil, a única filial fora da Rússia; 2) Santa Catarina recebe anualmente mais de 6.000 bailarinos no maior Festival de Dança do Mundo em Joinville; 3) Santa Catarina é o Estado brasileiro que mantém inúmeros Festivais de Dança nos mais variados estilos; somente no Vale do Itajaí são em média de 15 festivais de dança que mobilizam escolas de ensinos formais e não formais, anualmente; 4) a região, de grande tradição europeia, possui diversos grupos de danças tradicionais vinculados aos mais diversos clubes que mantém a tradição com a dança; 5) em Blumenau existem diversos projetos sociais como o Pró-família, escolas públicas e particulares que possuem projetos envolvendo diversos estilos de dança; 6) encontra-se em Blumenau a Escola Pró-Dança, vinculada ao Teatro Carlos Gomes, de tradicional ensino de diversos estilos de dança, ainda a escola de Dança da Master Ballet, na Academia Master com um projeto significativo na área da dança clássica; 7) em Gaspar existe um projeto de dança nas escolas e CDIs, bem como na Associação Amigos da Dança possuem grande atividade que envolve diversos estilos de dança; 8) na área escolar a Fesporte, órgão do governo do Estado, circula Santa Catarina com a caravana da Dança e o Festival Escolar Dança Catarina, no qual professores de Educação Física e de Artes se desdobram para criação de trabalhos coreográficos por não possuírem uma formação de professores específica voltada para área da Dança.

\section{CONSIDERAÇÕES FINAIS}

As dezenas de concepções pedagógicas do ensino da dança nas faculdades, centros universitários e universidades brasileiras, propiciam, graças à nova LDB, a versatilidade a flexibilização, a diversidade de propostas e estruturas curriculares, elencando nacionalmente, instituições com perfis diferenciados, seguindo as suas vocações, de acordo com o contexto em que se encontram inseridas.

\footnotetext{
11 Para maiores informações, consultar: <http://www.furb.br/web/2164/servicos/outros-portais/servidor-furb/apresentação/ noticias/furb-lanca-primeiro-curso-de-danca-de-santa-catarina/6370>. Acesso: 05 ago. 2017.
} 
O reconhecimento da importância do ensino da linguagem artística da Dança, no ambiente escolar, bem como do profissional habilitado - licenciado - para tal, é ainda recente. Geralmente atrelalada aos conteúdos da Educação Física ou das Artes Visuais, a dança toma para si, hoje, a tarefa de se instaurar definitivamente como área artística autônoma, na escola, com conteúdos e modos de organização próprios.

A nova Lei de Diretrizes e Bases da Educação 9.394/96 prevê que o ensino de arte passa a ser obrigatório na educação básica, e os Parâmetros Curriculares Nacionais (PCNs) da área, apontam que as quatro linguagens artísticas - dança, música, teatro e artes visuais - devem ser contempladas. Mas, a realidade educacional brasileira, está, de fato, preparada para este impacto estrutural? Como se dá a integração das linguagens artísticas na escola?

\begin{abstract}
Quando a Lei de Diretrizes e Bases no 5.692/71 tornou a educação artística obrigatória nas escolas, trouxe uma proposta integradora das artes. Assim, qualquer atividade envolvendo exercícios musicais, plásticos e corporais era considerada pertinente, não necessitando de um aprofundamento das linguagens por parte dos profissionais dessa área. A ausência de conhecimentos específicos em dança resultou na utilização de movimentos de forma 'livre', sem intervenções, deixando o puro espontaneísmo prevalecer, ou na imitação de gestos e movimentos coreografados para serem utilizados em apresentações. A dança fazia parte, juntamente com o teatro, das artes cênicas que, ao lado da educação musical e das artes plásticas, constituíam o conjunto das 'atividades artísticas' desenvolvidas na escola. [...] A dança também se justificava nas escolas por sua contribuição com o desenvolvimento físico da criança, e por isso, esteve inserida muito mais no contexto da educação física do que no da arte. A dança era também utilizada como atividade recreativa e lúdica, não havendo, por parte das escolas, a intenção de promover seu ensino, mas sim de utiliza-la como forma de distração e compensação, para as disciplinas intelectuais, ou de ilustração de conteúdos de outras áreas (MORANDI 2006b, p. 82-83).
\end{abstract}

Enquanto área de conhecimento autônoma, a Dança tem um histórico pouco relevante, no ensino regular, possuindo as meras atribuições de: socializar, descontrair ou desinibir, mas, raramente sendo considerada como disciplina com conteúdos específicos, tais como o desenvolvimento da capacidade criativa, ampliação de vocabulário de movimentos, das habilidades motoras, consciência corporal, percepção espaço-temporal, expressão e comunicação não-verbal, sensibilidade estética, capacidade reflexiva e crítica em relação ao corpo em movimento, para citar alguns. 
Como apontam Isabel Marques e Fábio Brazil no livro Arte em questões (2012), o papel da escola é, certamente a abertura de espaços para que estudantes e professores de artes - leia-se, neste caso, a dança - se apropriem de experiências estéticas significativas. "Neste sentido, é papel definidor do professor e da escola oferecer aos estudantes possibilidades de criar e recriar [grifo meu] relações com a arte produzida e manifestada em sociedade" (MARQUES; BRAZIL, 2016, p. 53).

Mas, temos que nos fazer as seguintes perguntas: o ambiente escolar comporta estruturamente, os artistas-docentes formados nas áreas ou linguagens especifícas? 0 licenciado em Dança tem condições de assumir a função de 'professor de arte' na escola? O número de instituições de ensino superior em Dança no Brasil é suficiente e forma pessoal capacitado, numa média adequada, anualmente, para abarcar a realidade numérica e a demanda profissional, nas escolas da rede municipal, estadual e da rede privada?

Acredito que o momento atual, para a Dança, pode não ser o ideal, mas certamente merece crédito, pelos esforços e lutas constantes e apaixonadas, de toda a classe, ou seja, de todos os 'artistas da dança', empenhados em criar oportunidades efetivas, reais e legais, da inclusão desta linguagem no campo do ensino das artes na escola.

Iniciativas, como a proposta de implantação do curso de Licenciatura em Dança na Fundação Universidade Regional de Blumenau, portanto, devem ser aplaudidas e seus idealizadores homenageados.

Vida Longa e Próspera à Licenciatura em Dança da FURB!

\section{REFERÊNCIAS}

AQUINO, Dulce. Dança e universidade: desafio à vista. In: PEREIRA, Roberto e SOTER, Silvia (Orgs.). Lições de dança 3. Rio de Janeiro: UniverCidade, 2002 (p. 37-51).

BRASIL. Conselho Nacional de Educação. Conselho Pleno. Resolução CNE/CP no. 1 - de 18/02/2002. Institui Diretrizes Curriculares para a formação de professores da educação básica, em nível superior, curso de licenciatura, de graduação plena. Diário Oficial da União, Brasília, 9/04/2002a. Documento disponível em: <http://portal.mec.gov.br/seesp/arquivos/pdf/res1_2.pdf>. Acesso: 20 ago. 2017. 
Conselho Nacional de Educação. Conselho Pleno. Resolução CNE/CP no. 2 - de 19/02/2002. Institui a duração e a carga horária dos cursos de licenciatura, de graduação plena, de formação de professores da educação básica em nível superior. Diário Oficial da União, Brasília, 4/03/2002b. Documento disponível em: <http://portal.mec.gov.br/cne/arquivos/pdf/CP022002.pdf>. Acesso: 20 ago. 2017.

COSTAS, Ana Maria Rodriguez. Para além das normatizações, pulsar saberes. In: ROCHA, Thereza; Instituto Festival de Joinville (Orgs.). Graduações em dança no Brasil: o que será que será? Joinville: Nova Letra, 2016. (p. 128-136). Disponível em: $<$ http://www.ifdj.com.br/site/wp-content /uploads/2016/07/IX-Seminarios-de-DancaGraduacoes-em-Danca-no-Brasil_Varios-Autores.pdf> Acesso: 15 set. 2017.

MARINHO, Nirvana; TOMAZZONI, Airton; WOSNIAK, Cristiane (Orgs.). Algumas perguntas sobre dança e educação. Joinville-SC: Nova Letra, 2010.

MARQUES, Isabel; BRAZIL, Fábio. Arte em questões. São Paulo: Digitexto, 2012.

MORANDI, Carla. O descompasso da dança e da educação física. In: STRAZZACAPA, Márcia (Org.). Entre a arte e a docência: a formação do artista da dança. Campinas: Papirus, 2006a (p. 95-112).

A dança no ensino de arte. In: STRAZZACAPA, Márcia (Org.). Entre a arte e a docência: a formação do artista da dança. Campinas: Papirus, 2006b (p. 77-94).

SILVA, Eliana Rodrigues. Graduação em dança no Brasil: professor como orientador e aluno como protagonista. In: ROCHA, Thereza; Instituto Festival de Joinville (Orgs.). Graduações em dança no Brasil: o que será que será? Joinville: Nova Letra, 2016. (p. 30-36). Disponível em: $<$ http://www.ifdj.com.br/site/wp-content/uploads/2016/07/IX-Seminarios-de-DancaGraduacoes-em-Danca-no-Brasil_Varios-Autores.pdf> Acesso: 30 set. 2017.

STRAZZACAPPA, Márcia. O ensino de dança: dos cursos livres à universidade. In: STRAZZACAPA, Márcia (Org.). Entre a arte e a docência: a formação do artista da dança. Campinas: Papirus, 2006 (p. 11-14). 
TERRA, Ana. Onde se produz o artista da dança? In: MARINHO, Nirvana; TOMAZZONI, Airton; WOSNIAK, Cristiane (Orgs.). Algumas perguntas sobre dança e educação. Joinville-SC: Nova Letra, 2010. (p. 67-75). Disponível em: <http://www.ifdj.com.br/site/wpcontent/uploads/2015/10/III-Seminarios-de-Danca-Algumas-Perguntas-sobre-Danca-eEducacao.pdf> Acesso: 19 set. 2017.

WOSNIAK, Cristiane. Bacharelado e/ou licenciatura: quais são as opções do artista da dança no Brasil? In: MARINHO, Nirvana; TOMAZZONI, Airton; WOSNIAK, Cristiane (Orgs.). Algumas perguntas sobre dança e educação. Joinville-SC: Nova Letra, 2010. (p. 121-136). Disponível em: $\quad$ http://www.ifdj.com.br/site/wp-content/uploads/2015/10/III-Seminarios-de-DancaAlgumas-Perguntas-sobre-Danca-e-Educacao.pdf> Acesso: 21 set. 2017.

\section{Sites relacionados:}

Consultas sobre PCNs e LDB - <http://portal.mec.gov.br>. Acesso: 10 set. 2009.

Consulta sobre o Curso de Licenciatura em Dança da FURB:

<http://www.furb.br/web/5171/cursos /graduação/cursos/danca/apresentacao>. Acesso: 04 ago. 2017.

Portal de Notícias da FURB: <http://www.furb.br/web/2164/servicos/outrosportais/servidor-furb/apresentacao/noticias/furb-lanca-primeiro-curso-de-danca-desanta-catarina/6370>. Acesso: 05 ago. 2017.

Consultas sobre Cursos de Graduação em Dança:

$<$ www.educacaosuperior.inep.com.br/funcional/lista_cursos.asp $>$. Acesso: 28 set. 2017.

Consultas sobre a Classificação Brasileira de Ocupações:

<http://www.mtecbo.gov.br/cbosite/pages/ home.jsf>. Acesso: 10 ago. 2017. 